\title{
KARIES GIGI DAN TOOTH LOST INDEX (TLI) PADA IBU MAJELIS TAKLIM PERKOTAAN
}

\author{
Eka Anggreni, Rikawarastuti \\ Jurusan Keperawatan Gigi Poltekkes Kemenkes Jakarta I
}

\begin{abstract}
WHO expects to achieve maximum functionality teeth population aged 35-44 years must be at least 20 teeth were still there. Lost Tooth Index (TLI) means the percentage of the number of permanent teeth were missing against the number of dental caries (DMF-T). This study aimed to describe TLI urban woman. The research method cross-sectional study in a population of women majelis taklim in the Village Cilandak Barat, South Jakarta. Samples are 30 people who obtained purposively. The data used are primary data through questionnaires to determine the characteristic of respondents (age) and intraoral examination to obtain the data of experience permanent dental caries (DMF-T) and TLI. The results showed urban women aged $35-44$ years experience $1-2$ lost teeth, while the age of $45-54$ years $\geq 5$ tooth loss. The average missing 4.83 with numbers DMF-T on average 6.66 so that the figure of $72.52 \%$ TLI. Urban women suffered a loss of $72.52 \%$ due to dental caries. Suggested respondents maintain dental and oral hygiene to reduce the risk of missing teeth due to caries and for mothers who have lost teeth using dental prostheses.
\end{abstract}

Keyword: karies, tooth lost index.

\section{PENDAHULUAN}

Kehilangan gigi (tooth lost) menunjukkan hilangnya beberapa struktur orofasial seperti jaringan tulang, saraf, reseptor dan otot yang mengakibatkan fungsi orofasial berkurang. Penurunan jumlah gigi berdampak negatif terhadap kualitas hidup manusia karena berkaitan dengan kemampuan mengunyah, berbicara, dan mengurangi penampilan (Brennan et al. 2008). Kehilangan gigi merupakan hasil yang mencerminkan riwayat penyakit gigi, sikap, perilaku kesehatan gigi, dan perawatan gigi seseorang, serta ketersediaan dan aksesibilitas ke layanan kesehatan gigi. Faktor lain yang mempengaruhi adalah status sosial ekonomi, jenis kelamin, dan umur seseorang (Bernabé \& Sheiham 2014).

Umur harapan hidup manusia semakin meningkat dan didukung dengan tren orang dewasa lanjut mempertahankan gigi alami mereka sampai di kemudian hari. Namun, kehilangan gigi dan konsekuensinya tetap menjadi kenyataan pada populasi geriatri. kesehatan mulut yang buruk dan mengabaikan langkah-langkah kebersihan sering menyebabkan kerusakan yang cepat dari gigigeligi (Muller \& Schimmel 2010). Hilangnya gigi tetap pada orang dewasa umumnya disebabkan oleh proses penuaan, perawatan mulut yang buruk, atau cedera/trauma benturan. Data terbaru melaporkan bahwa orang dewasa Amerika yang berusia 20-64 tahun memiliki rata-rata 25 gigi. Hasil studi lain juga menunjukkan hubungan yang signifikan antara umur dan kehilangan gigi pada orang tua (Chung et al. 2011) (Zhu \& Hollis 2014).

Beberapa studi telah menunjukkan bahwa kehilangan gigi pada orang dewasa dikaitkan dengan peningkatan risiko penyakit kronis seperti obesitas, penyakit kardiovaskuler pembuluh darah, dan diabetes. Hubungan antara kehilangan gigi dan penyakit kronis yakni terjadinya perubahan asupan makanan seperti diet seimbang yang sangat berkontribusi untuk mengurangi risiko penyakit kronis. Bagi orangorang yang kehilangan gigi, kemampuan mengunyah mereka berkurang karena mengalami kurang gigi. Akibatnya, terjadi perubahan pilihan diet mereka seperti pengurangan asupan makanan keras termasuk buah-buahan dan sayuran tertentu sehingga mengurangi asupan nutrisi tertentu (Zhu \& Hollis 2014).

Kehilangan gigi menyiratkan gangguan fungsional yang cukup besar yang hanya sebagian dapat dikompensasi dengan cara prostodontik (Muller \& Schimmel 2010). Kehilangan ini dapat berhubungan dengan masalah karies gigi dan penyakit periodontal. Meskipun upaya pencegahan karies dan penyakit periodontal meningkat seiring kemajuan teknik dan bahan restoratif namun kehilangan gigi tetap menjadi kenyataan klinis 
di usia tua (Muller \& Schimmel 2010) (Gigi et al. 2014).

Beberapa studi menyatakan bahwa karies dan penyakit periodontal merupakan penyebab utama terjadinya kehilangan gigi (Brennan et al. 2008) (Muller \& Schimmel 2010) (Gigi et al. 2014). Di Indonesia tahun 2013 dilakukan survey yang menunjukkan penduduk DKI mengalami gigi hilang pada kelompok umur 35 - 44 tahun sebanyak $72.9 \%$ dan umur 45 - 54 tahun sebesar $63.7 \%$ (Kemenkes 2013). Tidak ada laporan apakah kehilangan gigi disebabkan oleh karies ataukah sebab sebab lain. Namun, diperoleh data tingkat keparahan kerusakan gigi/ karies gigi (DMF-T) di mana perempuan memiliki indeks DMF-T yang lebih tinggi dibandingkan lakilaki (Kemenkes 2013). Oleh karena itu, tujuan penelitian ini untuk mendeskripsikan pengalaman karies gigi tetap (DMF-T) melalui pemeriksaan decay, missing, filling serta angka kehilangan gigi akibat karies (Toot Loss Index) pada ibu-ibu majelis taklim di daerah perkotaan.

\section{METODE}

\section{Jenis Penelitian}

Pendekatan penelitian ini berupa deskriptif dengan rancangan cross-sectional studies. Lokasi penelitian adalah Kelurahan Pondok Labu Kecamatan Cilandak Barat, Jakarta Selatan dan waktu penelitian dilakukan pada bulan Maret - Mei 2016.

\section{Populasi dan Sampel}

Populasi penelitian adalah ibu-ibu majelis taklim di Kecamatan Cilandak Barat, Jakarta Selatan, Provinsi DKI Jakarta dengan besar sampel 30 orang. Sampel penelitian diperoleh secara purposive sampling. Kriteria inklusi penelitian adalah ibu yang terlibat aktif di majelis taklim di Kelurahan Pondok Labu, berumur 35 - 54 tahun dan bersedia menjadi responden sedangkan kriteria eksklusi adalah ibu majelis taklim yang memiliki penyakit kronis (jantung, diabetes, dan hipertensi).

\section{Variabel dan Pengukuran}

Variabel yang diukur adalah umur dan angka TLI. Pengumpulan data dilakukan dengan memperoleh ijin (inform consent) dari responden. Data yang gunakan merupakan data primer dengan mengisi kuesioner untuk mengetahui umur responden dan melakukan pemeriksaan intraoral untuk memperoleh angka TLI. Angka TLI adalah persentase antara jumlah gigi hilang dibagi DMF-T, Indeks DMF-T ialah indeks yang digunakan pada gigi tetap untuk menunjukkan banyaknya gigi yang terkena karies. Status karies adalah suatu kondisi yang menggambarkan pengalaman karies seseorang yang dihitung dengan menggunakan indeks DMF-T (Decayed missing filling theeth) menurut Klein $\mathrm{H}$, Palmer CE dan Knutson JW. D (Decayed) merupakan lubang gigi akibat dekalsifikasi jaringan email gigi, terlihat keputih-putihan atau kecoklatan, dan ujung sonde terasa menyangkut pada kavitas. M (Missing) adalah hilangnya gigi tetap akibat telah tanggal atau dicabut, atau karies gigi tetap yang diindikasikan untuk pencabutan. F (Filling) merupakan tambalan atau tumpatan gigi tetap baik secara tetap maupun tambalan sementara. Kategori DMF-T menurut WHO yakni sangat rendah $(0,8-1,1)$, rendah $(1,2-2,6)$, sedang (2,7-4,4), tinggi $(4,5-6,5)$, sangat tinggi $(>6,6)$.

Alat yang digunakan dalam pemeriksaan intraoral yakni bak instrument, kaca mulut, sonde, excavator, pinset dan bahan berupa kapas, alcohol, masker, sarung tangan, tisu, handuk dan sabun cuci. Pemeriksaan klinis dilakukan oleh mahasiswa keperawatan gigi yang terlatih di bawah pengawasan langsung dari peneliti utama.

\section{Analisis Data}

Analisis data berupa analisis univariat. Data dianalisis dengan teknik deskriptif, dan penyajian data dengan tabel dan dalam angka rata-rata dan persentase.

\section{HASIL PENELITIAN}

Tabel 1. menunjukkan sebaran umur responden dan tabel 2 menggambarkan hasil pemeriksaan intraoral terhadap decay, missing dan filling responden penelitian ini.

Tabel 1. Umur responden

\begin{tabular}{ccc}
\hline Umur & Jumlah & Persentase(\%) \\
\hline $35-44$ tahun & 14 & 46.6 \\
$45-54$ tahun & 16 & 53.3 \\
\hline
\end{tabular}


Tabel 2. Gambaran D, M, dan F Responden

\begin{tabular}{ccccc}
\hline \multirow{2}{*}{ Kategori } & \multicolumn{2}{c}{ Ada } & \multicolumn{2}{c}{ Tidak ada } \\
\cline { 2 - 5 } & $\mathrm{n}$ & $\%$ & $\mathrm{n}$ & $\%$ \\
\hline $\mathrm{D}$ (decay) & 19 & 63.3 & 11 & 36.3 \\
M (missing) & 26 & 86.6 & 4 & 13.3 \\
F (Filling) & 3 & 10 & 27 & 90 \\
\hline
\end{tabular}

Gambaran status pengalaman karies gigi tetap (DMF-T) responden ditunjukkan pada Tabel 3. Toth lost Index (TLI) dapat dihitung menggunakan rumus dengan hasil TLI responden sebesar $72.5 \%$.

$\mathrm{TLI}=\mathrm{M} /(\mathrm{DMF}-\mathrm{T}) \times 100 \%$

\section{TLI $=145 / 200 \times 100 \%$ $=\mathbf{7 2 . 5 \%}$}

Berarti $72.5 \%$ kehilangan gigi pada responden disebabkan oleh karies gigi. Gambaran TLI responden berdasarkan kelompok umur digambarkan pada Tabel 4.

Tabel 3. Gambaran DMF-Tresponden

\begin{tabular}{cccc}
\hline Kategori & Jumlah & Rata-Rata & \% \\
\hline D (decay) & 44 & 1.46 & 22 \\
M (missing) & 145 & 4.83 & 72.5 \\
F (Filling) & 11 & 0.36 & 5.5 \\
DMF-T & 200 & 6.65 & 100 \\
\hline
\end{tabular}

Tabel 4. TLI berdasarkan Umur

\begin{tabular}{|c|c|c|c|c|c|c|c|c|c|c|}
\hline \multirow{3}{*}{$\begin{array}{c}\text { Kategori } \\
\text { Umur }\end{array}$} & \multicolumn{8}{|c|}{ Jumlah Tooth Lost } & \multirow{2}{*}{\multicolumn{2}{|c|}{ Jumlah }} \\
\hline & \multicolumn{2}{|c|}{ Tidak ada } & \multicolumn{2}{|c|}{$1-2$ gigi } & \multicolumn{2}{|c|}{$3-4$ gigi } & \multicolumn{2}{|c|}{$\geq 5$ gigi } & & \\
\hline & $\mathrm{n}$ & $\%$ & $\mathrm{n}$ & $\%$ & $\mathrm{n}$ & $\%$ & $\mathrm{n}$ & $\%$ & $\mathrm{n}$ & $\%$ \\
\hline $35-44$ tahun & 1 & 7.2 & 7 & 50 & 3 & 21.4 & 3 & 21.4 & 14 & 46.6 \\
\hline $45-54$ tahun & 3 & 18.7 & 0 & 0 & 3 & 18.7 & 10 & 62.6 & 16 & 57.3 \\
\hline Jumlah & 4 & 25.9 & 7 & 50 & 6 & 40.1 & 13 & 84 & 30 & 100 \\
\hline
\end{tabular}

\section{PEMBAHASAN}

Kehilangan gigi memberikan efek negatif terhadap kualitas hidup dan kesehatan umum (Guciz Dogan \& Gokalp 2012). Kehilangan gigi menyebabkan menurunnya kemampuan mengunyah pada lansia sehingga mempengaruhi pola makan lansia, kekecewaan psikologis yang berkaitan dengan masalah gigi dan ketidakpuasan dengan penampilan karena masalah dengan gigi, mulut, atau gigi palsu (Brennan et al. 2008).

Padahal, prevalensi kehilangan gigi pada usia lanjut (lansia) masih sangat tinggi. Kehilangan gigi kebanyakan mulai terjadi pada rahang bawah (Mayulu 2015). Perawatan kesehatan gigi dan mulut pada orang dewasa masih belum memadai, padahal permintaan untuk layanan ini sangat besar seperti pergantian gigi alami dan penggunaan prostesa palsu. Kehilangan gigi pada umur di atas 50 tahun terutama dikaitkan dengan karies gigi termasuk karies akar gigi (Rihs et al. 2009). Oleh karena itu, banyak penelitian yang membuktikan adanya hubungan antara umur dengan kehilangan gigi (Chung et al. 2011) (Kandelman et al. 2008) (Bernabe \& Sheiham 2014). Tabel 4 menunjukkan bahwa pada umur 35 - 54 tahun terdapat $86,7 \%$ responden mengalami kehilangan gigi minimal 1 buah. Semakin tua umur semakin banyak kehilangan gigi. Namun, jumlah gigi yang dimiliki responden masih dalam batas aman kualitas hidup menurut WHO yakni sebanyak 20 gigi (Kandelman et al. 2008).

Faktor sosiodemografi lain yang mempengaruhi adalah jenis kelamin/ gender. Perempuan diindikasikan menjadi faktor risiko untuk mengalami kehilangan gigi. Hal ini 
dihubungkan dengan peran hormonal perempuan untuk fungsi menstruasi, hamil, dan melahirkan. Gender juga berhubungan dengan status sosial ekonomi seperti pendapatan, pendidikan, dan pekerjaan yang berkaitan dengan penggunaan perawatan gigi dan asuransi gigi (Russell et al. 2013). Penelitian ini mendukung hasil penelitian sebelumnya bahwa perempuan memang berpotensi mengalami kehilangan gigi dengan dilakukannya penelitian pada ibu majelis taklim sehingga mayoritas ibu majelis taklim mengalami kehilangan gigi.

Hilangnya gigi dapat disebabkan oleh hilangnya perlekatan periodontal dan tulang alveolar akibat resesi gingival dan perubahan jaringan periodontal pada lansia (Mayulu 2015) dapat pula akibat karies, perawatan gigi yang buruk, dan trauma (Chung et al. 2011). Penelitian ini menggambarkan tingginya angka kehilangan gigi akibat kariespada ibu majelis taklim di perkotaan. Dari hasil penelitian diperoleh angka pengalaman karies (DMF-T) rata-rata responden 6.65 artinya setiap responden memiliki $6-7$ buah gigi yang mengalami kerusakan akibat karies. Sebuah penelitian di Turki tahun 2012 menemukan bahwa indeks DMF-T sangat bervariasi dan signifikan berhubungan dengan jenis kelamin, umur, dan tempat tinggal. Kelompok umur yang lebih tua, perempuan dan tinggal di pedesaan akan memiliki DMF-T yang lebih tinggi (Guciz Dogan \& Gokalp 2012).

Selain itu, hasil penelitian juga menggambarkan jumlah decay pada responden dengan rata-rata 1.46 artinya responden memiliki gigi berlubang $1-2$ gigi perorang, jumlah missing pada responden dengan rata-rata 4.83 artinya responden memiliki gigi hilang $4-$ 5 gigi dan jumlah filling pada responden dengan rata-rata 0.36 menunjukkan hanya sedikit responden yang mempunyai gigi dengan tambalan baik/tetap. Hal ini menggambarkan buruknya kesehatan gigi dan mulut pada ibu majelis taklim di perkotaan.

Angka kehilangan gigi akibat karies didapatkan dari angka Tooth Lost Index (TLI) sebesar $72.5 \%$ artinya sebagian besar dari responden mengalami kehilangan gigi akibat karies. Kehilangan gigi erat kaitannya dengan umur. Kelompok umur $34-44$ tahun memiliki kehilangan gigi $1-2$ gigi sedangkan umur $45-$ 54 tahun mengalami kehilangan gigi $5-6$ gigi.

Penelitian ini masih memiliki beberapa keterbatasan. Pertama, jenis penelitiannya adalah cross-sectional studies sehingga peneliti tidak bisa menentukan arah hubungan antara umur dengan jumlah gigi yang hilang akibat karies. Kedua, karena penelitian sudah difokuskan pada jenis kelamin/ gender perempuan maka peneliti tidak dapat menunjukkan perbedaan antara jenis kelamin. Ketiga, meskipun peneliti telah menggunakan indeks DMFT untuk mengetahui kehilangan gigi akibat karies namun faktor kesehatan periodontal, penggunaan prostesa untuk mengevaluasi status kesehatan mulut tidak dilibatkan dalam penelitian. Temuan penelitian ini adalah memberikan kontribusi untuk pengembangan program kesehatan dan promosi mulut untuk lansia.

\section{KESIMPULAN}

DMF-T rata-rata 6.65 artinya setiap ibu majelis taklim memiliki 6-7 buah gigi yang mengalami kerusakan akibat karies. Angka DMF-T mempengaruhi angka hilangnya gigi sehingga menyebabkan masih tingginya angka Tooth Lost Index (TLI) pada ibu-ibu majelis taklim sehingga perlu menjaga kesehatan gigi dan mulut dan menggunakan protesa untuk membantu fungsi gigi lebih maksimal.

\section{UCAPAN TERIMA KASIH}

Ucapan terima kasih tak terhingga kepada Endah Setyoningrum (mahasiswa tingkat akhir Jurusan Keperawatan Gigi Poltekkes Kemenkes Jakarta I) yang telah melakukan pengumpulan data di lapangan dan Kelurahan Pondok Labu yang memberikan ijin tempat penelitian.

\section{DAFTAR PUSTAKA}

Bernabe, E. \& Sheiham, A. (2014). Tooth loss in the United Kingdom - Trends in social inequalities: An age-period-and-cohort analysis. PLOS ONE, 9(8).

Brennan, D.S., Spencer, A.J. \& RobertsThomson, K.F. (2008). Tooth loss, chewing ability and quality of life. Quality of Life Research, 17(2), pp.227235.

Chung, S.Y. et al. (2011). The strength of age effect on tooth loss and periodontal condition in Korean elderly. Archives of Gerontology and Geriatrics, 53(2).

Gigi, J.K. et al. (2014). Gambaran pola kehilangan gigi sebagian pada masyarakat desa Guntung Ujung Kabupaten Banjar. Dentino Jurnal Kedokteran Gigi, II(2), pp.138-143.

Guciz Dogan, B. \& Gokalp, S. (2012). Tooth 
loss and edentulism in the Turkish elderly. Archives of Gerontology and Geriatrics, 54(2), pp.162-166.

Kandelman, D., Petersen, P.E. \& Ueda, H. (2008). Oral health, general health, and quality of life in older people. Special Care in Dentistry, 28(6), pp.224-236.

Kemenkes, B. (2013). Riset kesehatan dasar. , pp.118-119.

Mayulu, N. (2015). Pola kehilangan gigi pada masyarakat desa Roong Kecamatan Tondano Barat Minahasa Induk. e-GiGi, 3(2), pp. $508-514$.

Muller, F. \& Schimmel, M. (2010). Tooth loss and dental prostheses in the oldest old. European Geriatric Medicine, 1(4), pp.239-243.

Rihs, L.B., da Silva, D.D. \& de Sousa,
M.D.L.R. (2009). Dental caries and tooth loss in adults in a Brazilian southeastern state. Journal of applied oral science: revista FOB, 17(5), pp.392-396.

Russell, S.L. et al. (2013). Sex/gender differences in tooth loss and edentulism. Historical perspectives, biological factors, and sociologic reasons. Dental Clinics of North America, 57(2), pp.317337.

Zhu, Y. \& Hollis, J.H. (2014). Tooth loss and its association with dietary intake and diet quality in American adults. Journal of Dentistry, 42 (11), pp.1428-1435. Available at: http://dx.doi.org/10.1016/j. jdent.2014.08.012. 